

\title{
Editorial
}

\section{Student research: the future of paramedicine}

\author{
Peter O'Meara BHA, MPP, PhD ${ }^{1}$
}

\author{
Affiliation: \\ ${ }^{1}$ La Trobe University, Victoria
}

For the first time since the establishment of a paramedicine peer-reviewed journal in Australia and New Zealand, a special edition is being published specifically for student contributions. This is an important juncture in the evolution of our profession that recognises the importance of the next generation of paramedic practitioners, scholars and leaders. It really does mark a departure from our vocational training roots to a tertiary educated health profession that works in partnership and alongside other health professions (1).

At a personal level, this edition is even more significant as we celebrate the 40th anniversary of the paramedic conference that was held in Melbourne in 1974. The fledgling Australian Institute of Ambulance Officers, now Paramedics Australasia, organised the event and many ambulance services throughout Australia supported staff who wished to attend. Even at that time, student members were recognised and given significant roles in the event. I well remember as a young student the nervousness that I felt when officially thanking the after dinner speaker, the late Dr John Birrell, the long-standing and eminent Victoria Police surgeon who contributed so much to child safety and improving road safety throughout the world (2).

This special edition showcases contemporary student work from both Australia and New Zealand on a diverse range of topics addressing clinical (3-5) and systems issues (6,7). From Australia, Lynsey Smit (3) provides a literature review to ask whether antibiotic prophylaxis in pre-hospital trauma care has a place in the civilian context, while Yu-Tung Chang (6) compares anaphylaxis guidelines from around the world. Christian Winship, an honours student at the time, looks at pre-hospital cardiac arrests attended by fire fighter first responders in Melbourne (5). The New Zealand contribution offers a wide range of clinical topics, as well as raising questions about paramedic education and retention in the workforce $(4,7)$. One message that emerged from the papers was the importance of addressing the issues that confront paramedics and paramedic services that operate in remote or extreme environments, irrespective of whether services are publicly funded, privately operated or provided through the military $(8,9)$. These papers collectively provide readers with a look into the future of the paramedicine profession in terms of roles, clinical interventions and professional identity as we adapt to increased knowledge, improvements in technology and the changing needs of our communities (10). These authors and other student paramedics, along with our recent graduates in the workforce, share a heavy responsibility to take the profession into the future through a combination of scholarship, professionalism and engagement in the development of paramedic-related policy $(11,12)$.

The scholarly work published in this edition has value in its own right as a contribution to our growing knowledge base and as pointer to our future practice. More importantly, it provides a window through which we can see our future leaders (13). The challenge for us all, whether we are experienced paramedics, scholars or industry leaders, is to ask what we can do to nurture the next generation in whatever roles they pursue. In terms of research and academic scholarship, we can all contribute to the development of a future paramedicine research agenda and facilitate the necessary resources to encourage and support research and the dissemination of new knowledge and understanding (14). Through research, scholarship and active support, we can all help our health discipline make a meaningful difference to the lives of the patients and communities that are our central motivation.

Dr Peter O'Meara

Editor

Australasian Journal of Paramedicine 


\section{References}

1. O'Brien K, Moore A, Dawson D, Hartley P. An Australian story: paramedic education and practice in transition. Australasian Journal of Paramedicine 2014;11(3).

2. The Royal Australasian College of Physicians. College Roll: Birrell, John Henry Winter. Available at: www.racp.edu.au/page/ library/college-roll/college-roll-detail\&id=580.

3. Smit L, Boyle M. Should systematic antibiotic prophylaxis be part of civilian pre-hospital trauma care for open or penetrating wounds? A review of the literature. Australasian Journal of Paramedicine 2014;11(5).

4. Tunnage B. Fostering a research culture in paramedicine: selected proceedings from the 2011-2013 Paramedic Research Forum at Auckland University of Technology. Australasian Journal of Paramedicine 2014;11(5).

5. Winship C, Boyle M, Williams B. Out of hospital cardiac arrest management by first responders: retrospective review of a fire fighter first responder program. Australasian Journal of Paramedicine 2014;11(5).

6. Chang Y-T, Boyle M. Comparison of anaphylaxis diagnostic criteria and management guidelines for the pre-hospital setting. Australasian Journal of Paramedicine 2014;11(5).

7. Morrison TA, Tunnage B. Māori participation in paramedic education and the emergency medical services workforce in New Zealand: A report. Australasian Journal of Paramedicine 2014;11(5).

8. Higgins J, Tippett V, O'Brien A, et al., editors. Expanding the scope of paramedic practice in rural and remote isolated communities. 15th World Congress on Disaster and Emergency Medicine; 2007; Amsterdam, The Netherlands.

9. O'Meara P, Tourle V, Stirling C, Walker J, Pedler D. Extending the paramedic role in rural Australia: a story of flexibility and innovation. Rural Remote Health 2012;12(2):1-13.

10. O'Meara P. So how can we frame our identity? Journal of Paramedic Practice 2011;3(2).

11. Jacobs I. Pre-hospital care: a plea for more research. Emerg Med 2000;12(3):175-6.

12. Williams B, Brown T, Onsman A. From stretcher-bearer to paramedic: the Australian paramedics' move towards professionalisation. Australasian Journal of Paramedicine 2012;7(4).

13. Ferguson L, O'Meara P. Management and Leadership. In: Curtis K, Ramsden C, Lord B, editors. Emergency and Trauma Care. Sydney: Mosby Elsevier; 2011.

14. Jensen J, Blanchard I, Bigham B, Dainty K, Socha D, Carter A, et al. Canadian National EMS Research Agenda: Dalhousie University Division of EMS and the University of Toronto Li Ka Shing Knowledge Institute (RESCU)2012. 